entrance requirements to universities, and the promise of some progress. All this will help, but it may not unfortunately be enough. For it is possible that the causes of the drift from science in the schools are closer to the foundations of the British education system, and lie in the unique pattern of specialization in the years before university. It may be significant that science holds its own with the humanities in the early years at school, and that it loses ground when young people are expectedat 16 or 17-to make an almost final choice. May not some potential scientists be protesting that they would first like to speak French more fluently, and to learn what Keynes was all about? And may they not be right? In other words, a proper study of the disaffection of potential scientists demands a study of the balance of the curriculum-at schools and, to some extent, at university. Even if such a study should raise the prospect of a fouryear undergraduate course, the Dainton committee should not flinch from adding this to its already overcrowded brief.

\section{BY RAIL TO FRANCE?}

$\mathrm{M}^{\mathrm{s}}$ R. STANLEY RAYMOND, the chairman of British Rail, may have spoken more wisely than he knew when he said, on March 14, that if the digging of a tunnel beneath the English Channel did not begin this year, it had better be abandoned altogether. For the case for the Channel Tunnel is no longer overwhelming. If the tunnel could have been built at the end of the nineteenth century, it would no doubt have been a great boon to Britain and to France. But now, as Mr. Raymond seems to feel, the passage of time is against it. Other ways of crossing this narrow strip of water have become progressively more efficient and attractive, while the consequences of the existence of a tunnel have become more disconcerting. Hovercraft may be cheap, fast and flexible to use. The claims of the bridge-builders strengthen as the years go by. Then in Kent and in the Pas de Calais town and traffic planners are already wondering how they will manage if a tunnel should be built. The problems of driving trains through narrow apertures at the speeds now being dreamt of have yet to be faced. And there is no knowing that a single tunnel could accommodate the growth of travel across the English Channel since the last traffic survey, and the extrapolation based on it, nearly a decade ago.

These, of course, are not the doubts that worry $\mathrm{Mr}$. Raymond. $\mathrm{He}$ is faced with the need to provide for the potential travellers and for the freight which seems to increase alarmingly in volume whenever the prospects of Britain joining the European Economic Community brighten, however fleetingly. Should British Rail put its faith in a tunnel, or should it buy new ships or hovercraft instead? That, on the face of it, is a commercial decision to be made. In reality, however, the problem is more complicated. In spite of all the surveys which have been carried out, the tunnel remains something of an unknown quantity. How much would it really cost? How effectively would the undoubted virtues of a through journey by rail persuade users to fight their way to the loading points? And, if it were successful, what would be the social costs in congestion and in disturbance of funnelling a large proportion of an important traffic through a single route? Matters like these have not yet been studied with the care that they deserve. The case for yet another survey is overwhelming. It is true that repeated surveys are frequently no more than means of postponing impor. tant decisions, but they also share some of the rare benefits of the trials by ordeal popular in the Middle Ages. If, indeed, the delay of one more year should be intoler. able, the Channel Tunnel had better be abandoned now, before it is begun.

\section{PHYSICS-GROWTH OR DECAY?}

$\mathrm{T}$ HE threat of unaccustomed lack of funds for research in physics in the United States is one of the spectres to emerge from a report now published by the Physics Survey Committee of the U.S. National Academy of Sciences*. "For the first time in the history of physics in the United States, budgetary limitations threaten our ability even to sustain productive continuing activity in many segments of physics." Almost literally, professional physicists are wondering where the next accelerator is to come from.

The Physics Survey Committee is one of several committees set up two years ago by the Committee on Science and Public Policy of the National Academy. The intention is to make a comprehensive and systematic survey of the condition of science and its need of support. (The committee on chemistry has already reported (Nature, $209,541 ; 1966)$.)

The sense of discontent in what the report has to say about federal support for physics springs chiefly from recent fluctuations in the money available and from changes in policies for spending it. "When sharp variations occur - either upward or downward-from a steady growth rate in financial support for physics, serious difficulties can occur."

The Committee says that when funds suddenly become scarce, the first research to suffer tends to be the comparatively unspectacular work at universities by post-graduate students in training. The "high visibility" laboratories, as they are called, "tend to pass a disproportionately large share of the cut-back on to smaller projects, thus striking a disproportionately large blow at the training of new scientists". The Committee also argues that at times of sudden shortage, new researchers suffer more than established men; according to figures from the U.S. National Science Foundation, only 7 per cent of the proposals for research by now investigators in 1963-65 were granted. The committee also protests at the danger that unexpected surpluses can lead to the construction of facilities which cannot be fully used, and at the imbalances that can arise when government agencies impose external (and sometimes arbitrary) limits on the proportions of available funds to be spent on services and on materials.

But how much money should there be ? The Committee acknowledges that any answer to this question must be hedged with qualifications. It also proclaims that "physics does not seek to grow without limit... Science is clearly becoming a more extensive part of modern life, but science in general and physics in particular do not threaten to consume the gross national product". Briefly, however, the Committee would like to see an annual growth rate of 16 per cent between 1963 and the end of this decade - a figure which it modestly compares with a rate of growth of between 20 and 30 per cent in the late 'fifties and early 'sixties.

* Report on the Present State of U.S. Physics and its Requirements for Future Growth, National Academy of Sciences, Washington, D.C. 5.00 dollars. 